\section{DILATED CORONARY SINUS IN NEONATES}

Michael Sammaan. UK

\subsection{6/bmjpo-2021-RCPCH.52}

Background The coronary sinus is a venous system situated at the back of the atrioventricular junction and draining into the right atrium, which can be assessed from various echocardiography angles. In certain cases, the coronary sinus can be dilated by volume or more rarely by pressure overload.

Objectives To evaluate the efficacy of detecting coronary sinus in neonates and to determine the standard values of coronary sinus measurements. To highlight the importance of functional echocardiography in the assessment of the causes of dilation.

Methods Screening with echocardiography was done in 30 neonatal patients who were admitted to our unit (median 34week gestation). Coronary sinus was evaluated in the fourchamber view ( $83 \%$ of cases), subcostal view $(8 \%)$ or parasternal short-axis view (12\%). The second group of two patients with a dilated coronary sinus was compared with the normal group.

Results Adequate coronary sinus imaging was done in 97.4 per cent of normal neonates. The diameter of the coronary sinus varied from $1 \mathrm{~mm}$ to $3.4 \mathrm{~mm}$. The two neonates with a dilated coronary sinus had a persistent left superior vena cava, which flowed into it. In the abnormal group, the diameter of the coronary sinus was nearly three times greater. CS should be assessed and indexed to the body surface area as part of standard echocardiography screening. The dilated coronary sinus (+2 Z score) has several causes, including persistent left superior vena caves in our case, a total anomaly in the pulmonary venous drainage, pathological hepatic venous drainage or sinus ASD. A thorough evaluation of the Right Ventricle (RV) function is required, as dilated CS is one of the characteristics of RV dysfunction.

Conclusions Dilated CS can be contributed by many factors and detailed imaging is recommended, in a few patients, a contrast echo can help in visualising in details CS and rule out deroofing.

\section{CROUCH GAIT IN DRAVET SYNDROME: CLINICAL, PRACTICAL AND PERSONAL OBSERVATIONS}

Georgia Raniolo. UK

\subsection{6/bmjpo-2021-RCPCH.53}

Background Dravet syndrome (DS) is an aggressive developmental and genetic epileptic encephalopathy. Along with pharmacoresistant epileptic seizures, this rare disease is characterised by cognitive impairment, speech and language disability and, notably, mobility problems. Observational reports have shed some light on the progression of the disease, but the aetiology of DS is still poorly understood. The syndrome is further characterised by a progressive non-specific decline in gait. There is limited literature about the natural history of progressive gait decline in the context of DS.

Objectives In order to explore DS and its significant impact on patients' and their families, this work will discuss personal experiences caring for a patient with this condition, followed by a systematic literature review focusing on the aetiology and natural history of gait abnormalities in DS, with reflections regarding the aforementioned case.
Abstract 93 Table 1 Table showing the key studies utilised for this literature review.

\begin{tabular}{|c|c|c|c|c|}
\hline n & $\begin{array}{l}\text { Source of } \\
\text { Journal } \\
\text { Article }\end{array}$ & $\begin{array}{l}\text { Lead Author, } \\
\text { Year of } \\
\text { Publication }\end{array}$ & Title & $\begin{array}{l}\text { Number of } \\
\text { participants }\end{array}$ \\
\hline 1 & PubMed & Black, 2016 & Crouch Gait and Dravet Syndrome & 12 \\
\hline 2 & PubMed & $\begin{array}{l}\text { Di Marco, } \\
2019\end{array}$ & $\begin{array}{l}\text { Gait abnormalities in people with } \\
\text { Dravet Syndrome: A cross sectional } \\
\text { multi-centre study }\end{array}$ & 71 \\
\hline 3 & PubMed & Gitiaux, 2016 & $\begin{array}{l}\text { Motor neuropathy contributes to } \\
\text { couching in patients with Dravet } \\
\text { Syndrome }\end{array}$ & 12 \\
\hline 4 & PubMed & Rilstone, 2012 & $\begin{array}{l}\text { Dravet syndrome: seizure control and } \\
\text { gait in adults with different SCN1A } \\
\text { mutations }\end{array}$ & 10 \\
\hline \multirow[t]{2}{*}{5} & PubMed & Rodda, 2012 & $\begin{array}{l}\text { Progressive gait deterioration in } \\
\text { adolescents with Dravet Syndrome }\end{array}$ & 26 \\
\hline & & & & Total: 131 \\
\hline
\end{tabular}

Methods The search via PubMed produced a total of nine articles. Four articles were excluded from the in-depth literature review as they focused on treatment options for patients with DS rather than the impact on crouch gait in children with DS. Results The total number of children studied in this systematic review is 131 . The final five articles are listed in table 1 .

The literature reveals that children with DS show progressive gait deterioration that is noticeable in early childhood but has particular impact in the second decade of life. The literature suggests that children under 6 have a normal or variable gait pattern with possible features of joint hypermobility. Beyond this age, the progressive decline in gait is more heterogenous. The literature indicates that there may be an evolution element to the gait deterioration that requires further investigation.

Over the course of six years caring for Child X, I have witnessed a serious visible decline in their mobility. The change has been gradual but the impact this has had on their independence is massive. Child $\mathrm{X}$ follows a classic trajectory of progressive gait deterioration, as observed by the majority of authors in more than half of the population cohort, in the literature review.

Conclusions Caring for a young child with DS, has provided me with a unique insight and first-hand account of the deterioration of their mobility, as well as the impact this has on their quality of life. More consideration is now being directed towards how families cope in their daily lives with the multiple aspects of DS.

\section{EVALUATION OF USE OF TECHNOLOGY AND ITS IMPACT ON GLYCEMIC CONTROL IN CHILDREN \& YOUNG PEOPLE WITH TYPE1 DIABETES MELLITUS}

Suman Fathima, Neemisha Jain. UK

\subsection{6/bmjpo-2021-RCPCH.54}

Background Technology in Diabetes has been rapidly evolving in order to help optimize blood glucose(BG) control in diabetic patients.

Objectives Analysis of glycemic control(GC) in children and young people with Type 1 Diabetes Mellitus(CYP T1D) using 